\title{
The Eldon Dedini Collection: Broccoli, Babes, and Everything Else
}

\author{
WENDY PFLUG \\ The Obio State University, Columbus, Obio, USA
}

\begin{abstract}
Archival practice has traditionally overlooked the informational value that objects and ephemera can provide to documents; their usefulness is limited to being an exhibit item or novelty. This article discusses the challenges and opportunities found in the management of objects and ephemera found in a collection of a cartoonist's papers. Learning and adapting new perspectives about objects from related fields demonstrates that objects can also support and extend understanding of documents when kept together. The paper concludes with a series of questions in order for an archivist to evaluate these items to recognize their value to documents within a collection.
\end{abstract}

KEYWORDS appraisal, artifacts, documents, Eldon Dedini, ephemera, papers of cartoonists, three-dimensional objects

\section{INTRODUCTION}

Archivists highly value written documents, but three-dimensional objects and ephemera are materials that usually fall out of the scope of most institutions. These materials are thought of as the odds and ends, which inevitably arrive whenever collections are acquired and are considered detritus to be sorted through in order to find the records of value. If they are kept, usually it is because of a donor's wish or "there is no place else for them to go." If an individual object is recognized as valuable it is usually transferred to a museum. Otherwise the objects and ephemera are set aside, given a

(c) Wendy Pflug

The title is reference to the 2005 retrospective exhibit of Dedini's art "Babes \& Broccoli," curated by Dennis Renault and held at the Sasoontsi Gallery in Salinas, California.

Address correspondence to Wendy Pflug, Billy Ireland Cartoon Library \& Museum, The Ohio State University, Sullivant Hall, 1813 N. High Street, Columbus, OH 43210. E-mail: pflug.9@osu.edu 
low priority in the backlog, or grouped together in a miscellaneous series, their form taking precedence over their function. They are hastily described, thus ensuring that they likely will not be discoverable to researchers. In an environment of limited resources, it is not considered wise to invest much time and energy on materials that may have little benefit in terms of research use.

However, further exploration regarding the informational value of objects to researchers challenges this assumption. Scholars in other disciplines argue that objects and ephemera enhance textual documents or are capable of providing insights not necessarily found elsewhere. Disciplines such as art history, anthropology, archeology, history, historic preservation, museum studies, and other social sciences have used interpretation of objects and ephemera to provide primary source information. Historian Chris E. Makepeace, sees the value of ephemera to researchers as providing "information which might not be available from any other source." ${ }^{1}$ This is especially true when researching underground movements, underrepresented groups, or the daily lives of ordinary people. The miscellaneous odds and ends such as product packaging, leaflets, advertisements, tickets, posters, tokens, bills, comics, and trinkets are sometimes the only evidence of existence left behind by such groups. The interdisciplinary field of material culture studies in particular supports the view that objects are representatives and analyzes the uses and meanings people put towards objects. ${ }^{2}$

Archival practices suggest that objects should be separated from documents, but the separation of object from written record would most likely result in loss of context found in the connection between the materials. Can objects and ephemera be considered documents, meaning they should not be separated from related textual sources? The conventional thought is that objects belong in museums and documents belong in archives, but why is this assumption accepted? Because unavoidably these odds and ends will continue to arrive with acquired materials, what does an archivist do when confronted with a collection that contains objects, ephemera, and documents?

These questions concerning documents, objects, and ephemera arose during the survey of the unprocessed materials in the Eldon Dedini Collection at The Ohio State University Billy Ireland Cartoon Library \& Museum. Eldon Dedini was a cartoonist who was best known for his cartoons that appeared in Playboy magazine. Dedini's New York Times obituary credits his cartoons for establishing the magazine's aesthetic, "[H]is sexually brash satyrs in joyful pursuit of astoundingly proportioned, equally lusty nymphs became as much a Playboy's trademark as lascivious advice columns." ${ }^{3}$ Besides his notable work for Playboy his career included thousands of cartoons in publications such as The New Yorker, Esquire, and Sports Illustrated. In addition, Dedini illustrated many books and advertisements, including the character "Broccoli Wokkily" for a campaign of stand-out advertisements for Mann's Packaging that lasted nearly a decade. Dedini was considered the master of 
the gag cartoon, which refers to a single-panel illustration often published in a magazine; its purpose is intended to provoke a quick chuckle. ${ }^{4}$ Dedini was most proud of the written gags in his cartoons. In a newspaper interview he once said, "the gag is the whole secret of cartooning. Style alone will never sell a bum joke. So you can draw. A million people can draw. The question is are you funny?" To this end, in the documentary Dedini: A Life of Cartoons he said, "every day that I wake-up I try to be as funny as hell." 6

To achieve the perfect set-up for his one-liners, Dedini devoured information for inspiration, keeping voluminous idea files containing article clippings, product packaging, flyers, tickets, photographs, and catalogs. His Carmel, California home was a testament to his active mind; it was filled with pillars of periodicals, books, and research files. When asked in an interview where he got his ideas, he answered, "they're in a box in the basement." While this answer was an example of Dedini's quick wit, there was some truth behind the statement. He would typically fill a folder with rough sketches and the materials that inspired him such as clippings, pamphlets, flyers, and notes gathered from a variety of sources. Once full, the folder was placed in a filing cabinet or box and stored in one of the many locations, including a tiny cellar, ready to be called upon when needed for inspiration. "The lines usually come first," ${ }^{8}$ he once explained and then he would begin to furiously draw, producing nearly 20 to 30 sketches in one day, often working seven days a week.

Shortly before his passing in 2006, the entire contents of Dedini's Carmel home were inventoried, packed, and sent to The Ohio State University in Columbus, Ohio. The collection consisted of over 1,100 pieces of original art and nearly 130 boxes of archives. Per museum practice the art was separated, each individual piece given a unique finding number, and cataloged using the content management system software, PastPerfect. The archival materials consisted of records documenting the business side of a freelance illustration career, rough sketches, correspondence with other contemporary cartoonists, and records from his involvement in professional cartooning organizations. Found shuffled amongst the archives were Dedini's many idea files and research materials used to create his gag cartoons. These idea files, which ranged in subject matter from Flemish Painters to Archie Comics Digest, contained many objects and ephemera along with documents. When writing a processing plan for this collection, an archivist initially suggested weeding the idea files to only contain documents and sketches, while de-accessioning the objects and ephemera. However, as more was learned about Dedini's work, ${ }^{9}$ the informational value to be found in what was initially dismissed as "not archival" material (objects and ephemera) became apparent. It seemed that the contents of the idea files extended the peripheral artistic process of this cartoonist. Even the file folders themselves offered insight into this process; illustrated with doodles and annotated with notes about the project's directions. The connection between the mixed formats found within a file 
became evident when sorting through several folders titled, "Lenin."10 The folders contained rough cartoons featuring the former Soviet leader, along with variety of clippings that were seemingly unrelated to each other. A closer inspection of the clippings to the sketches revealed a connection. A book review of journalist P. J. O'Rourke's Holidays in Hell seemed to inspire a series of drawings imagining Lenin as a tourist, with captions titled "Lenin in New Jersey" and "Lenin in Zurich." A clipping from Newsweek on Donna Wood, a ballet dancer appearing in a production of Fontessa and Friends, led to a series of rough sketches about Lenin and ballet. One sketch showed Lenin and a female ballet dancer in the same pose as Donna Wood from a production still. In another box one could compare his rough sketches of golfers from magazine clippings to the final product, a character known as the "Duke of Del Monte," 11 which also found was embroidered on a golf cap and silk-screened on a golf towel. To separate the rough sketch from the ephemeral source that inspired it would break the context in which it was created. Dedini's voluminous archives provided insight into his creative process, which was not found elsewhere.

Going through the collection, it became clear that more information was needed to learn about the relationship between objects and documents. As mentioned previously, archival training has often taught that threedimensional objects were the purview of museums, whereas archives handled paper. What if the object and record need to stay together to provide a full understanding? What does one do when a collection has both objects and documents that are of equal importance? What do museums do with their objects? Could a document be an artifact, or could an artifact be a document? Is it useful to adapt perspectives from related fields such as those that study objects to preserve the context of the creation of Dedini's ideas? What are some of the issues concerning objects and ephemera in collections? While archives should not aim to comprehensively collect art, objects, artifacts, and ephemera, these materials need to be kept together and their connection documented when they enhance the written record or provide a context that would be lost due to separation of the materials. The Eldon Dedini Collection is an example of three-dimensional objects and ephemera, along with written documents that provides a larger understanding of the artist's work.

\section{CURRENT UNDERSTANDING OF OBJECTS IN ARCHIVES}

Where did the assumption arise that archival records can only be textual documents? Most early literature assigns to archives the narrow scope of noncurrent records "drawn up or used in the course of an administrative or executive transaction (whether public or private) of which itself formed a part." 12 For his purposes in Archives Administration, Hilary Jenkinson 
describes documents as "manuscripts," "type-scripts," and "printed matter,"13 words that imply that archives consist of written documents. The Society of American Archivists' (SAA) A Glossary of Archival and Records Terminology, defines a document as "text fixed on paper." 14 It also defines documents more broadly to include a variety of formats such as maps, photographs, and audiovisual materials. However, the physical formats of these documents are mostly two-dimensional or, according to the Glossary, are known as a "fourcorners document," defined as "Writing, graphics, or other information that can be reasonably displayed on a two-dimensional surface." 15 This definition expands understanding of a document to contain both text and image, but it does not specifically mention three-dimensional objects as documents. It is interesting to note that the Glossary lists a synonym for document as "writing," 16 indicating that documents are still thought of as textual.

The Glossary uses the word realia, which is "a three-dimensional object," and offers synonyms such as "artifact; object; replica; specimen."17 To expand on the definition, the glossary distinguishes an artifact as "a man-made physical object" 18 and notes that artifacts may be preserved as a record if the object's purpose is to "document a design or function." The definition does not indicate that an object should be kept if it helps to expand understanding of written records. These definitions infer that most three-dimensional objects serve as ornamental items to archival collections and should only be considered documents if they meet a narrow criteria. A related form of realia, ephemera, is defined as printed material, which conforms to one aspect of Jenkinson's description of documents as textual but is usually not considered a document because it is "created for a specific, limited purpose, and generally designed to be discarded after use." ${ }^{19}$ Ephemera are kept because of an association to person or event. The very definition of ephemera depicts it as every day disposable items; not documents worthy of retention.

\section{PRACTICAL CHALLENGES OF OBJECTS}

Besides an initial bias against considering objects and ephemera as documents, there are many practical challenges that make archivists hesitant to accept them. The preservation challenges of three-dimensional objects and nonstandard sizes of ephemera are distinct from those of four-corners documents. The recommended preservation treatment of objects within collections usually involves separating them from the textual records to avoid damage to the paper documents. The SAA Archival Fundamentals Series Preserving Archives and Manuscripts suggests that objects or materials of irregular size, which "are damaging to adjacent or surrounding material because of their size, shape, or composition but that are integral to the collection may be either filed separately or kept within their file sequence 
but physically separated." ${ }^{20}$ Basic preservation of objects seems to suggest treating these materials as larger textual records and storing in acid-free containers. However, it does not account for the varying size and shape of objects, which do not always fit neatly into a box. Although it is practical to separate large items from small items to prevent damage, this will result in several different sequences of items stored in multiple locations, making retrieval confusing or difficult for staff. Another disadvantage to separating objects is that the multiple sequences will result in wasted shelf space or wasted space inside a box due to accommodating irregular sizes. Contributing to preservation challenges of ephemera and objects is the possibility that the material's function was transient and was not intended to endure the test of time. Three-dimensional ephemeral objects such as locks of hair and decorated eggshells are organic materials that will eventually degrade over time. Acid-free housing and storage in climate-controlled stacks may not be sufficient to ensure long-term preservation of these objects.

Recent literature suggests that appraisal and processing decisions about objects should not be different from decisions made about documents. Objects should provide information about the creators or subjects of a collection, similar to the way in which other documents are appraised and retained ${ }^{21}$ and not kept because the object is unique or because of the person who once owned it. Objects should provide information about the creators or subjects of a collection, similar to the way in which traditional documents are appraised and retained. However, the information that is provided by objects about a subject or the creators can be lost if the form of the item takes priority over its function. The likely result of treating objects by their form is that all items will be grouped into a miscellaneous series where they may lose significance and connection to written records.

Jill Robin Severn gave an example of the object's form taking precedence over its function that is found in many collections of political papers: "so even if button, bumper stickers, and even bandwagons [are] created clearly in the context of a campaign activity [and] belong logically with a campaign or political series, often they are removed from this original functional context and arranged by form as a series of memorabilia along with unrelated items such as desk sets, plaques, and ceremonial shelves." 22 The inclination to separate objects into their own series treats objects in collections as an anomaly that must conform to accepted practices whether they fit or not. The challenges that artifacts pose to intellectual control are also a great concern to repositories. When objects are transferred to a repository within a larger collection, the simple act of packing the materials can destroy the interrelationship of the object to documents. When objects and ephemera are separated from their original environments, the connections are not always apparent, which leaves archivists unprepared or unable to establish a connection between the object and the record. Verbal explanations or demonstrations from the donor may be needed to make the connection. 
The absence of significant literature on how to manage objects and ephemera in archives leads to the question of how other institutions are currently managing objects within their collections. The Association of Research Libraries' (ARL) SPEC Kit 333: Art and Artifact Management surveyed member libraries on the systems and techniques that are currently used to gain intellectual control over art and artifacts. The results indicated that the tools and procedures to manage collections containing artifacts vary greatly, not only among the member libraries, but also amid different collections within a single institution. Data gathered in the survey also indicated a lack of a consistent approach and that "on average institutions are using three different tools to manage art objects." 23 The most common methods for establishing intellectual control of objects are finding aids, MARC records, local databases, and spreadsheets. It is interesting to note that these tools are the same as those used to describe collections that consist of documents. This would indicate that objects are being described to existing standards that are familiar to an archivist, but may not adequately fit. Lack of best practices for intellectual control has resulted in multiple systems and inconsistent metadata, making discovery difficult for patrons. Have the lack of clear standards also contributed to the low use of objects, which is one of cited reasons objects have a lower priority among archivists? Of particular interest, SPEC Kit 333 notes that many institutions struggle with issues of managing art and artifacts within collections, but "without a sense that other institutions share the same problem." ${ }^{24}$ It seems that this statement attests to the need for a larger discussion among archivists regarding the place of objects within, and management of, these collections.

Archivists are averse to keeping three-dimensional objects, artifacts, or ephemera because of the practical storage, preservation, and intellectual control challenges, which can be a considerable drain on limited resources. Reluctance also occurs because archivists do not want to take materials that cannot be cared for properly. While archivists prefer not to divide a collection between two separate institutions, most would rather see the objects transferred to a museum with the resources to care for the materials. Severn surmises this rationale can help perpetuate the assumption that records belong in archives, whereas artifacts belong in museums, and with limited resources, archivists "must concentrate [their] energy on real records of the archives, the written (and spoken) record." 25

\section{THE VALUE OF OBJECTS TO ARCHIVES}

The issue of an object's place in the archives is one that has received attention in recent years; scholars have encouraged a re-examination of archival perspectives and practices in regards to objects. Severn and Gloria Meraz are proponents of the value of objects within archives' collections to enhance 
understanding of written documents and offer a more complete historical record. Severn takes the view that people express themselves, and the times they once lived in, through objects, functioning similarly to a diary or other written and spoken records. The possessions of a particular person give information on their tastes, social status, and wealth. Meraz admits that this information about a person can be learned directly from written documents, but artifacts allow researchers the opportunity to interpret the relationship between the object and the subject themselves. This interaction between document and object further benefits the researcher by allowing him "to describe the relationship between that object and the subject both in historical and contemporary terms, ${ }^{26}$ providing a holistic context of history. The objects found in the Eldon Dedini Collection are important because they provide insight into his creative process. For example, objects such as his pencils, pens, charcoal, and crayons allow researchers to examine the tools used to create his artwork. A researcher can observe the original art to appreciate color and line, but examining the physical tools that created the art can provide unique insights into techniques. Although these tools are readily used to create art, this may not be true in the future. Dedini's pencils and pens act as an artifact used to create a cartoon.

The everyday nature of ephemera provides a more complete view of Dedini that cannot necessarily be detected through his artwork. Although he was most known for works that appeared in urbane national publications, Dedini was born and raised in King City, California, a small agricultural town in the Salinas Valley. After finishing schooling he moved back to Monterey County and met deadlines through the mail. Dedini's devotion to the Salinas Valley becomes evident through examination of ephemera found in the collection. Pamphlets, flyers, clippings, printed fact sheets, event tickets, and programs indicate his involvement in many local organizations, charities, and preservation efforts of area landmarks such as Cannery Row. Although he is most known for his lusty Playboy cartoons, he was devoted to his family and to his Episcopal faith. Throughout his files are evidence of his faith found in prayer sheets, daily devotional guides, and materials from religious retreats. He was an active member All Saints Episcopal Church; he drew a series of cartoons called, "Brother Larry," a hapless monk that was the set-up for (church-appropriate) gags in the church newsletters "Parish Patters" and "Mission Bell."

\section{ARCHIVAL BOND AND MATERIAL CULTURE}

The interrelationship of archival records to objects is examined in the case study "Separated at Appraisal" 27 by Katie Rudolph. The study was conducted at the Wisconsin Historical Society on appraising and processing a collection that contained both objects and records. Rudolph advocates for archivists 
to see the connection of objects to traditional records and to document this interrelationship in the archival description. To make the connections between records and objects during appraisal, she introduces the concept of archival bond that occurs between records. Archival bond was first used by Luciana Duranti in her scholarship on the integrity of electronic records. Duranti asserts that archival bond is "originary" and records created as part of the same activity belong together in the same grouping as they are evidence of "the cause-effect connection between records." 28 Archival bond calls for the function of objects, created from the same activity as records, to take the precedence rather than the format of the object. Rudolph states the importance of archival bond as "necessary and determined because without it objects would exist in a vacuum without an ability to provide information about history or biography." 29 To help establish an archival bond, she encourages archivists to look beyond archival theory and become familiar with concepts from the field of material culture studies, which supports the scholarly inquiry into the uses and the meaning of objects by people. An understanding of the discipline will allow archivists to understand that objects are capable of documenting biography and history as well as function and design. Material culture studies view objects as representative of culture and makes unique contributions to an understanding of the workings of individuals and societies.

\section{PERSPECTIVES FROM MUSEUMS}

Although Rudolph suggests incorporating ideas from material culture studies when appraising objects, the related field of museum studies also offers useful perspectives. Museums concentrate on preserving culture, often through objects that were once useful and that represent a past concept or event. Although archives and museums are perceived as fundamentally different, they share many similarities. On a basic level, both institutions have similar missions to collect information and to preserve and make it accessible. However, the practices and philosophies used to attain that goal differ. This leads to museums and archives focusing on improvement to existing practices and approaches exclusively within their separate realms. Although museums have concentrated on materials as representations of culture, archives have focused more on the informational needs that collections provide as primary source materials. For example, returning to Jenkinson's definition of archives as noncurrent records once created and used in the course of a transaction, it can be suggested that the records in the archives are like tools that were once used in the conduct of an activity, similar to artifacts in a museum. Hugh Taylor argued that archivists often do not see the significance of documents beyond their factual content. However, documents can be viewed as a tool used in the conduct of affairs, similar to museum artifacts. He suggested that 
documents can be viewed as created as the result of an action and that its creation often produced another response. Documents can be preserved as tools showing how an organization functioned when active. These records can have evidentiary impact as part of society's cultural heritage as representing how old systems once worked. Taylor highlighted that museums already view items in this manner and suggest that archivists can learn from them. ${ }^{30}$ This new perspective allows one to see commonalities and reinforces the idea that if objects and archives are separated, that understanding is lost, leading to an incomplete record. Adapting cultural perspectives from museums allows archivists to view objects as able to offer more to a collection besides exhibition or novelty.

Similarities between archives and museums materials become more apparent when examining their intuitional histories. Many early museums did not make a distinction between artifacts, records, and books. The material was displayed together in "cabinets of curiosities," which were originally collected by scholars in the 17th and 18th centuries. Museums were eventually established from these cabinets. In early institutions, curators did not separate materials by format but felt that "when people looked intensively at material objects they gained access to information that books could not provide." 31 These early curators believed that archives and artifacts were primary materials that could work in accord to further research. For example, one may realize the function of an object through tactile examination, but to understand the kind of value it had in society, that information is often found in documents.

\section{PUTTING APPRAISAL OF EPHEMERA AND OBJECTS INTO PRACTICE}

The combination of objects and ephemera with documents found within the Eldon Dedini Collection enhanced the materials providing interpretations about the artist and the context of his creations. The Billy Ireland Cartoon Library \& Museum at the Ohio State University is a comprehensive academic research facility with a primary mission to document printed cartoon and comic art. It seeks to offer a complete view into the work and life of an artist through original art and archives. It is inevitable that the institution will encounter more collections that contain objects, ephemera, and documents within the backlog of unprocessed materials. Similarly, the mixed materials of these collections will enhance understanding and provide insight into an artist; these would be lost if separated by format according to conventional archival practice. An archivist must understand the bond between objects and documents to prevent loss of context by separation. Building on concepts from related fields allows an archivist to see the relationship between objects, ephemera, and records that originate from the same activity. Archivists should 
emphasize what an object represents and make clear what information it conveys, providing reasons to keep certain objects over others.

To prevent the separation and ultimate loss of information, archivists at Billy Ireland created a series of questions to help frame appraisal decisions of objects not by their form, but by the contextual information they provide. The goal of these questions is to determine the significance, context, and rationale for keeping certain objects and documents together. This will help an archivist understand the value of the object to related documents and how to accurately describe it within discovery tools.

\section{Questions}

What Is the Physical Description and Condition of the Item?

The intention of this question is to understand practical challenges associated with the objects. The answers to this question may indicate preservation treatments, repairs, or specialized containers are needed. The goal is to clearly understand what special precautions need to be taken to ensure longevity of the item.

Things to consider:

- What type of physical material does the object consist of; is it composed of papers, plastic, wood, glass, photograph, metal, or a mixed format? Is it a single object or multiple objects? If multiple objects, how are they attached or connected?

- What size is the object? Can it fit on a shelf or within a pre-made box? Will a special container be needed to house the object?

- Does the object have any preservation issues such as, brittleness, color fading, detached or broken pieces, or other concerns?

- Does the material pose a safety concern, such as, sharp edges, toxic materials, or a hazard to handle in any way?

\section{Who CReated the Item? Is It Unique?}

These questions focus on the origin of the item, was it made by the creator of the collection? Does it have a direct association with a historically important person, place, event, or issue? The answers to these questions will emphasize the objects have value not just because it was owned by a particular person.

Things to consider:

- Who made this object?

- Is the object mass-produced, homemade, authentic, or a reproduction?

- What significance does the creator of the object have to the collection?

- Is this object likely to be found elsewhere? 
What Uses Were Made of THE ITEM?

This question considers if the object is important because of its original function or because of a secondary function.

Things to consider:

- What was the purpose of this item? Did it have a practical function such as that of a tool?

- Was the purpose of the object decorative?

- Which function, original or secondary, is more important to the understanding of the object in the collection?

Does the Item Have a Relationship to Another Document or Material in the COLleCtion?

This question examines if an object was a result of the same activity that created textual documents, which would indicate an archival bond between the materials.

Things to consider:

- Does the object help to give a more complete understanding of people or subjects within the collection?

- Was the object used in the act of creation of a piece of art, musical score, or literary work, or does it illustrate an idea or concept?

- Does it fit within the scope of the collection?

- How could it meet the information interests of various user groups served by the institution?

\section{Does the Item Have Exhibit Potential?}

This question takes into account potential visual interest of the object either by itself or displayed with other material. It can also identify any issues regarding appropriateness of scope to the collection or to the repository.

Things to consider:

- Does the object have any unusual or interesting physical features?

- Does the object have an aesthetic or artistic quality?

- Is the significance of the object enhanced when displayed with textual documents or other materials? Or conversely, is the significance of the textual document enhanced when displayed with the object?

Once these questions are answered, the archivist should have a clearer idea of the significance of the relationship of the objects to documents and can better decide how to maintain and document the bond when arranging 
and describing a collection. Recalling the observation made in the ARL Spec Kit 333: Art \& Artifact Management that many repositories struggle with the same issues of managing objects within collections, but without sense that other institutions struggle with the same problem: Sharing the series of questions might help other archivists facing similar dilemmas.

\section{CONCLUSION}

Conventional archival practice has typically overlooked the evidentiary value that objects and ephemera can provide to collections. Their usefulness to an archives repository is limited to a potential exhibit item or novelty. Although objects and ephemera do present many practical challenges to archivists, they can also support, complement, and expand the information found within documents. The Eldon Dedini Collection is an example of how objects and ephemera offer a more complete perspective of an artist known mostly for his cartoons of voluptuous women and advertisements for broccoli. The objects and ephemera found in the idea files help to recreate his artistic process, demonstrating how an article or image could provide inspiration and ultimately a finished cartoon. The insight gained from linking an object to a document would be lost and unlikely to be found through other records if these items were separated.

To establish a connection, it is helpful to learn concepts from related fields that study objects to understand a cause-effect relationship between documents and objects: one would not exist without the other and thus need to remain together. Although archives may not aim to amass objects and ephemera, they should not be apprehensive when these materials arrive within a collection. Learning and adapting new perspectives from archival bond theory, material culture studies, and museums allows one to see the similarities between records and objects, strengthening the concept that artifacts and archives support each other to provide a more complete understanding of history.

\section{NOTES}

1. Chris E. Makepeace, Ephemera: A Book on Its Collection, Conservation and Use (Brookfield, VT: Gower Publishing Company, 1985), 200.

2. Ian Woodward's Understanding Material Culture (London: Sage Publications, 2007) is a good source for the examination into material culture studies.

3. Douglas Martin, "Eldon Dedini, 84, Magazine Gag Cartoonist, Dies" New York Times, January 14, 2006. Available at http://www.nytimes.com/2006/01/14/arts/14dedini.html?_r =0

4. The impact of a gag cartoon is dependent on a caption that explains the illustration; often the picture and caption are each meaningless on its own.

5. Lisa Crawford Watson, "Dedini Redux," Monterey County Herald Go! Supplement, November 3-9, 2005, 3. 
6. Anson Musselman, Dedini: A Life in Cartoons (DVD). Directed by Anson Musselman. 2005. Bundled with Eldon Dedini, An Orgy of Playboy's Eldon Dedini (Seattle: Fantagraphics, 2006).

7. Irene Leon Masteller, "The World According to Eldon Dedini," Monterey County Herald, September 29, 1991, 16.

8. Leah Garchik, "Dedini Saw All His Jokes Go to Other People," San Francisco Sunday Examiner and Chronicle, August 10, 1980, 29.

9. This includes learning about the business side of magazine cartooning. In a 1991 interview from the Monterey County Herald (see Note 5) Dedini stated while he was under contract to The New Yorker and Playboy magazine, "only one out of every five cartoon ideas [is] actually published." The large amount of material within the idea files also gave an understanding of the demands of the cartooning industry.

10. [Box 102/Lenin], Eldon Dedini Collection, The Ohio State University Billy Ireland Cartoon Library \& Museum.

11. The "Duke of Del Monte" was a character Dedini designed as part of the logo for the renowned Del Monte Golf Course in Monterey, California. This character and logo is still used by the golf course today: http://www.pebblebeach.com/golf/del-monte-golf-course/membership.

12. Hilary Jenkinson. A Manual of Archive Administration (London: Percy Lund, Humphries \&Co, 1937), 11.

13. Ibid.

14. Richard Pearce-Moses, A Glossary of Archival and Records Terminology, Archival Fundamentals Series. (Chicago: Society of American Archivists, 2005). Available at http://www2. archivists.org/glossary/terms/d/document

15. Ibid. Definition of "four-corners document" available at http://www2.archivists.org/glossary/ terms/f/four-corners-document

16. Ibid. Definition of "document."

17. Ibid. Definition of "realia" available at http://www2.archivists.org/glossary/terms/r/realia

18. Ibid. Definition of "artifact" available at http://www2.archivists.org/glossary/terms/a/artifact

19. Ibid. Definition of "ephemera" available at http://www2.archivists.org/glossary/ terms/e/ephemera

20. Mary Lynn Ritzenthaler, Preserving Archives and Manuscripts (Chicago: SAA, 1993), 111

21. Pam S. Hackbart-Dean and Elizabeth A. Slomba, How to Manage Processing in Archives and Special Collections (Chicago: SAA, 2012), 53.

22. Jill Robin Severn, "Adventures in the Third-Dimension: Re-envisioning the Place of Artifacts in Archives," in An American Political Archives Reader, ed. Karen Dawley Paul et al. (Lanham, MD: Scarecrow Press, 2009), 227.

23. Morag Boyd and Jenny Robb, SPEC Kit 333: Art \& Artifact Management, (Washington, DC: American Research Libraries, 2012), 13.

24. Ibid., 17.

25. Severn, "Adventures in the Third Dimension," 223

26. Gloria Meraz, "Cultural Evidence: On the Common Ground between Archivists and Museologists," Provenance, Journal of the Society of Georgia Archivists 15 (1997): 23-24.

27. Katie Rudolph, "Separated at Appraisal: Maintaining the Archival Bond between Archives Collections and Museum Objects," Archival Issues 33, no.1 (2011): 25-39.

28. Luciana Duranti, "The Archival Bond," Archives and Museum Informatics 11 (1997): 213-218.

29. Rudolph, "Separated at Appraisal," 29.

30. Hugh Taylor, "Heritage' Revisited: Documents as Artifacts in the Context of Museums and Material Culture," Archivaria 40 (Fall 1995): 8-20.

31. Lisa M. Givens and Lianne McTavish, "What's Old is New Again: the Reconvergence of Libraries, Archives, and Museums in the Digital Age." The Library Quarterly 80, no.1 (January 2010), 8. 